\title{
CMEARTICLE
}

\section{Clinics in diagnostic imaging (165)}

Wan Ying $\underline{C h a n}^{1}$, MBBS, Hsueh Wen $\underline{\text { Cheong }}{ }^{1}$, MBBS, FRCR, Tien Jin $\underline{T a n}^{1}$, MBBS, FRCR
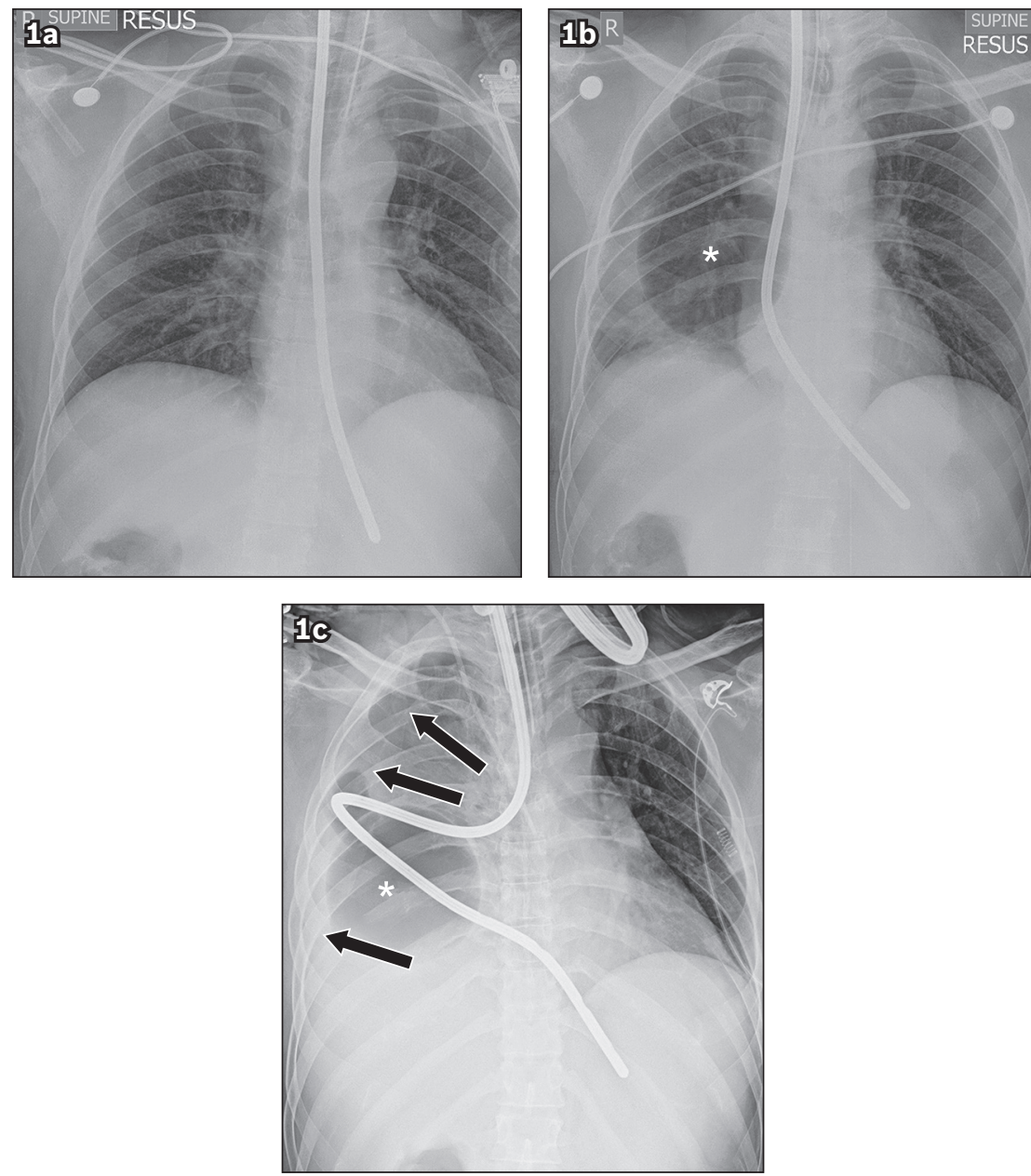

Fig. 1 Chest radiographs performed following the insertion of a Sengstaken-Blakemore tube (a) before and $(b$ \& $c)$ after the inflation of the gastric balloon.

\section{CASE PRESENTATION}

A 33-year-old Indian man with a history of alcohol dependence and prior treatment for bleeding gastro-oesophageal varices had a few seizure episodes while consuming alcohol (based on an eyewitness account). He was brought to the emergency department (ED), where he had an episode of haematemesis, as well as another episode of generalised tonic-clonic seizure shortly after. Computed tomography (CT) of the brain revealed significant intracranial haemorrhage with mass effect, and it was decided that the patient would require emergency craniotomy. Prior to endotracheal intubation to secure the patient's airway, the patient had another episode of massive haematemesis at the ED, and a SengstakenBlakemore (SB) tube was inserted in an attempt to arrest the upper gastrointestinal haemorrhage. Chest radiographs following the insertion of the SB tube before (Fig. 1a) and after (Fig. 1b) the inflation of the gastric balloon were obtained. Repeat chest radiography was performed following the craniotomy (Fig. 1c). What do the radiographs show? 


\section{IMAGE INTERPRETATION}

The initial chest radiograph (Fig. 1a) shows the SB tube, prior to the inflation of the gastric balloon, projected over the mediastinum, with the tip lying below the diaphragm and likely distal to the gastro-oesophageal junction. A chest radiograph obtained after the inflation of the gastric balloon (Fig. 1b) demonstrates a well-defined, round lucency $(*)$ corresponding to the inflated gastric balloon projected over the right hemithorax. Repeat chest radiography performed after emergency craniotomy (Fig. 1c) revealed further lateral displacement of the inflated gastric balloon ${ }^{*}$ ) and kinking of the SB tube, in association with new right-sided hydropneumothorax (arrows).

\section{DIAGNOSIS}

Oesophageal rupture secondary to malposition of an SB tube gastric balloon.

\section{CLINICAL COURSE}

The SB tube was subsequently removed and a right-sided chest tube was inserted. Approximately $1 \mathrm{~L}$ of blood was drained from the right pleural cavity. CT of the thorax (Fig. 2) demonstrated communication of the distal oesophageal lumen with the right pleural cavity (arrow), which corresponded with an oesophageal tear and showed the presence of rightsided haemopneumothorax. In view of the known intracranial haemorrhage with mass effect, the patient was deemed to be a high-risk surgical candidate, and repair of the oesophageal mural defect was deferred. A right-sided Cope loop catheter was inserted to passively drain the right pleural cavity. When the patient developed empyema, the Cope loop catheter was replaced under CT guidance with a large-bore chest tube, with the drainage tip of the chest tube positioned close to the site of oesophageal rupture. Subsequently, satisfactory drainage of right-sided empyema and a downward trend of the patient's inflammatory markers were observed. The patient's neurological status also stabilised, allowing for transfer from the intensive care unit to the general ward for continued management.

\section{DISCUSSION}

The SB tube has been used as a temporary measure for arresting oesophageal bleeding, with a reported success rate of $43 \%-84 \%$. ${ }^{(1,2)}$ The use of the SB tube as a therapeutic procedure for the immediate control of bleeding oesophageal varices before definitive shunt surgery has also been validated in several studies, including that of Bauer et al. ${ }^{(2)}$

Since its introduction in $1950,{ }^{(3)}$ several reports ${ }^{(1,2)}$ have described SB tube insertion-related complications such as aspiration pneumonia, airway obstruction, pressure necrosis, and oesophageal erosion and rupture. Collectively, such complications have been reported to occur in up to $35 \%$ of cases where an SB tube was used to arrest upper gastrointestinal haemorrhage. ${ }^{(4)}$ Significant patient mortality arising from these complications has also been reported. ${ }^{(4)}$ While oesophageal rupture, particularly following SB tube insertion, remains a relatively rare complication, it is often lethal. ${ }^{(5)}$ A study by

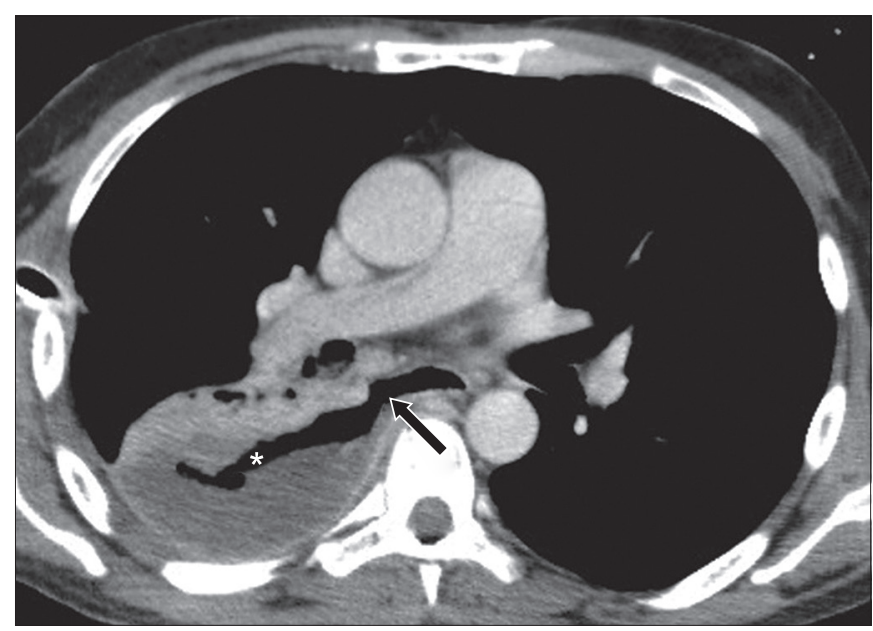

Fig. 2 Axial CT image of the thorax shows a tear of the right lateral wall of the distal oesophagus (arrow), in association with right-sided haemopneumothorax $\left({ }^{*}\right)$.

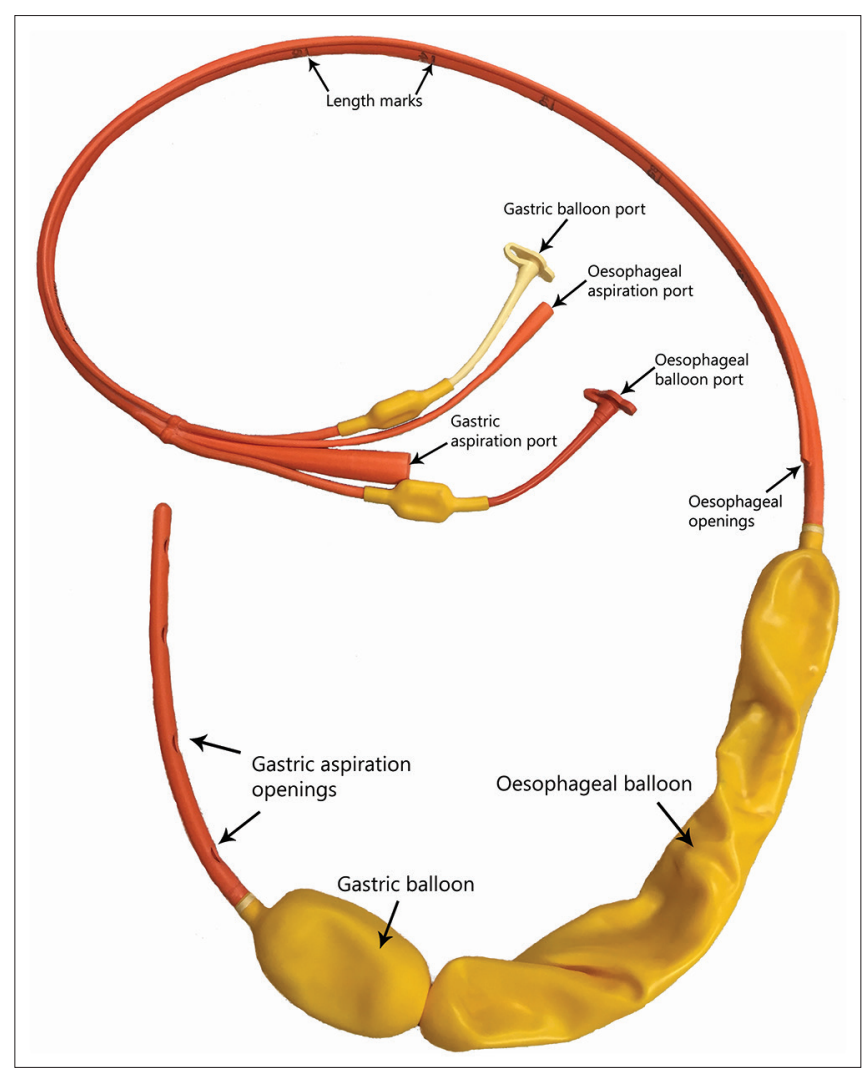

Fig. 3 Photograph shows a Sengstaken-Blakemore tube.

Brinster et al found that a delay in diagnosis and treatment of an oesophageal rupture by more than 24 hours significantly increased the patient mortality rate from $14 \%$ to $27 \%{ }^{(6)}$

Correct placement of an SB tube for the purpose of arresting upper gastrointestinal haemorrhage can be technically challenging. ${ }^{(1)}$ Various methods to aid and determine the correct placement of an SB tube have been described, including insertion of the SB tube to the 50- $\mathrm{cm}$ mark before inflation of the gastric balloon, ${ }^{(2)}$ securing the SB tube to a rigid face mask, ${ }^{(7)}$ auscultation to ascertain the intragastric placement of the distal tip ${ }^{(8)}$ performing chest radiography before and after inflation of the gastric balloon, ${ }^{(9)}$ sonographic assessment ${ }^{(10)}$ and endoscopic 


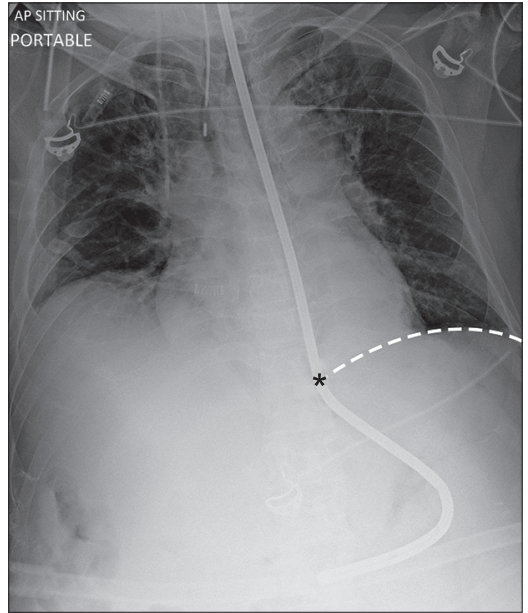

Fig. 4 Chest radiograph shows a correctly positioned Sengstaken-Blakemore tube prior to the inflation of the gastric balloon and the expected level of the gastroesophageal junction $\left(^{*}\right)$. The tip is seen well below the level of the diaphragm (broken line). AP: anteroposterior

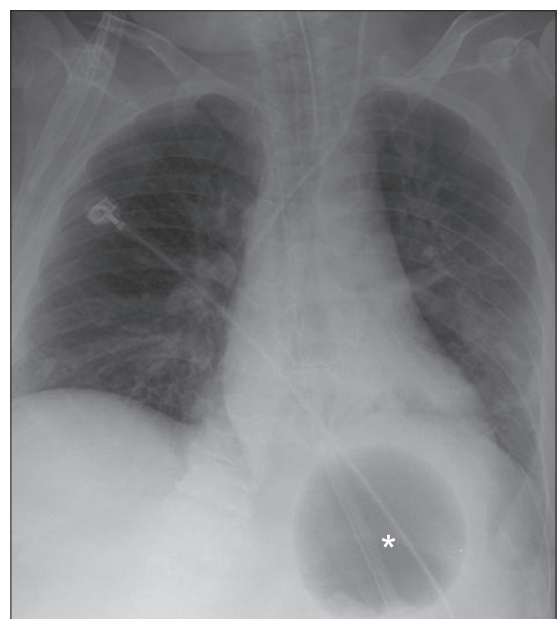

Fig. 5 Chest radiograph shows a correctly positioned Sengstaken-Blakemore tube following the inflation of the gastric balloon $\left({ }^{*}\right)$. A well-defined, round lucency is seen below the level of the diaphragm.

placement; ${ }^{(11)}$ the latter two methods require the presence of an experienced operator and the availability of ultrasonographic or endoscopic equipment, which may not always be the case in an emergency setting.

The SB tube comes with deflated oesophageal and gastric balloons, and two aspiration ports (Fig. 3). Prior to the inflation of the gastric balloon, the SB tube should be seen (on chest radiograph) descending centrally along the expected course of the thoracic oesophagus, with the distal tip well below the level of the diaphragm (Fig. 4). Following inflation, a well-defined, round lucency corresponding to the gastric balloon should be visualised below the diaphragm and over the expected location of the proximal stomach (Fig. 5). The radiological finding of a new lucency projected over the thoracic cavity following inflation of the SB tube gastric balloon has been described as being compatible with malposition of the gastric balloon. ${ }^{(8,12,13)}$ Radiological signs highly suspicious for associated oesophageal rupture include interval increase or appearance of unilateral pleural effusion, interval development of pneumothorax, or a combination of both. ${ }^{(6,14)}$
ABSTRACT Oesophageal rupture is a life-threatening complication of balloon tamponade for bleeding oesophageal varices. We herein describe the clinical course and imaging findings in a 33-year-old Indian man who had a Sengstaken-Blakemore (SB) tube inserted for uncontrolled haematemesis, which was unfortunately complicated by malposition of the gastric balloon with resultant oesophageal rupture. The inflated SB tube gastric balloon was visualised within the right hemithorax on chest radiography after the SB tube insertion. Further evaluation of the thorax on computed tomography confirmed the diagnosis of oesophageal rupture associated with right-sided haemopneumothorax. It is crucial for both the referring clinician and reporting radiologist to recognise early the imaging features of an incorrectly positioned SB tube gastric balloon, so as to ensure prompt intervention and a reduction in patient morbidity and mortality.

Keywords: chest radiograph, haematemesis, oesophageal rupture, oesophageal varices, Sengstaken-Blakemore tube

Awareness of the potential complications arising from the insertion of an SB tube for upper gastrointestinal haemorrhage and early recognition of the imaging features of an incorrectly positioned SB tube gastric balloon and an oesophageal rupture will enable both the referring clinician and reporting radiologist to carry out prompt interventions, which may lead to lower patient morbidity and mortality.

\section{ACKNOWLEDGEMENTS}

The authors thank Dr Andrew Kwek, Consultant Gastroenterologist, Changi General Hospital, Singapore, for providing the photograph of the SB tube (Fig. 3) and Dr Frank Gaillard (radiopedia.org), Consultant Radiologist, Royal Melbourne Hospital, Australia, for his kind permission to reuse the chest radiograph in Fig. 5.

\section{REFERENCES}

1. Vlavianos P, Gimson AE, Westaby D, Williams R. Balloon tamponade in variceal bleeding: use and misuse. BMJ 1989; 298:1158.

2. Bauer JJ, Kreel I, Kark AE. The use of the Sengstaken-Blakemore tube for immediate control of bleeding esophageal varices. Ann Surg 1974; 179:273-7.

3. Sengstaken RW, Blakemore AH. Balloon tamponage for the control of hemorrhage from esophageal varices. Ann Surg 1950; 131:781-9.

4. Conn HO, Simpson JA. Excessive mortality associated with balloon tamponade of bleeding varices. A critical reappraisal. JAMA 1967; 202:587-91.

5. Nielsen TS, Charles AV. Lethal esophageal rupture following treatment with Sengstaken-Blakemore tube in management of variceal bleeding: a 10-year autopsy study. Forensic Sci Int 2012; 222:e19-22.

6. Brinster CJ, Singhal S, Lee L, et al. Evolving options in the management of esophageal perforation. Ann Thorac Surg 2004; 77:1475-83.

7. Wallace A 3rd, Wallace WB, Balfour DC Jr. Use of head mask to aid esophageal tamponade. Gastroenterology 1953; 24:20-2.

8. Chong CF. Esophageal rupture due to Sengstaken-Blakemore tube misplacement. World J Gastroenterol 2005; 11:6563-5.

9. Crerar-Gilbert A. Oesophageal rupture in the course of conservative treatment of bleeding oesophageal varices. J Accid Emerg Med 1996; 13:225-7.

10. Lin AC, Hsu YH, Wang TL, Chong CF. Placement confirmation of Sengstaken-Blakemore tube by ultrasound. Emerg Med J 2006; 23:487. 
11. Lin TC, Bilir BM, Powis ME. Endoscopic placement of SengstakenBlakemore tube. J Clin Gastroenterol 2000; 31:29-32.

12. Rubin SA, Winsett MZ, Diner WC. Intrathoracic gastric balloon radiographic recognition of esophageal perforation. Gastrointest Radiol $1982 ; 7: 311-3$
13. Chien JY, Yu CJ. Images in clinical medicine. Malposition of a SengstakenBlakemore tube. N Engl J Med 2005; 352:e7.

14. Han SY, McElvein RB, Aldrete JS, Tishler JM. Perforation of the esophagus: correlation of site and cause with plain film findings. AJR Am J Roentgenol $1985 ; 145: 537-40$. 


\section{SINGAPORE MEDICAL COUNCIL CATEGORY 3B CME PROGRAMME} (Code SMJ 201602B)

Question 1. Bleeding oesophageal varices is an emergent life-threatening condition that may be managed

by the following temporising or definitive treatments:
(a) Transjugular intrahepatic portosystemic shunt procedure.
(b) Triphasic computed tomography of the liver.
(c) Sengstaken-Blakemore (SB) tube insertion.
(d) Insertion of a large-bore chest tube.

Question 2. Since its invention in the 1950s, the SB tube has been used for the following:
(a) Large-bore nasogastric tube to increase nutritional intake of patients.
(b) Drainage of otitis media with effusion.
(c) Temporary measure for acute bleeding oesophageal varices.
(d) Temporary biliary drainage for obstructive jaundice.

Question 3. Methods to aid or determine correct placement of an SB tube include:
(a) Inflating the oesophageal balloon first to anchor the SB tube before inflating the gastric balloon.
(b) Inserting the SB tube to the 50-cm mark before inflating the gastric balloon.
(c) Auscultation to ascertain the intragastric placement of the distal tip.
(d) Performing chest radiography before and after inflation of the gastric balloon.

Question 4. The following are complications of SB tube insertion:
(a) Airway obstruction.
(b) Aspiration pneumonia.
(c) Oesophageal rupture.
(d) Oesophageal varices.

Question 5. The following imaging findings are suspicious for oesophageal rupture after SB tube insertion:
(a) The presence of well-defined lucency over the proximal stomach.
(b) Interval increase or new unilateral pleural effusion.
(c) Interval development of pneumothorax.
(d) New well-defined lucency in the thoracic cavity.

\footnotetext{
Doctor's particulars:

Name in full

MCR number

Specialty:

Email address

\section{SUBMISSION INSTRUCTIONS:}

(1) Log on at the SMJ website: http://www.sma.org.sg/publications/smjcurrentissue.aspx and select the appropriate set of questions. (2) Provide your name, email address and MCR number. (3) Select your answers and click "Submit".

\section{RESULTS:}

(1) Answers will be published in the SMJ April 2016 issue. (2) The MCR numbers of successful candidates will be posted online at the SMJ website by 4 April 2016. (3) Passing mark is $60 \%$. No mark will be deducted for incorrect answers. (4) The SMJ editorial office will submit the list of successful candidates to the Singapore Medical Council. (5) One CME point is awarded for successful candidates.

Deadline for submission: (February 2016 SMJ 3B CME programme): 12 noon, 28 March 2016.
} 